\title{
China's urban expansion from 1990 to 2010 determined with satellite remote sensing
}

\author{
WANG Lei ${ }^{1,2}$, LI CongCong ${ }^{3}$, YING Qing ${ }^{1}$, CHENG Xiao ${ }^{1,3}$, WANG XiaoYi ${ }^{1}$, LI XueYan ${ }^{3}$, \\ HU LuanYun ${ }^{2}$, LIANG Lu ${ }^{2}$, YU Le ${ }^{2}$, HUANG HuaBing ${ }^{1} \&$ GONG Peng ${ }^{1,2,4^{*}}$ \\ ${ }^{1}$ State Key Laboratory of Remote Sensing Science, Jointly Sponsored by Institute of Remote Sensing Applications, Chinese Academy of Sciences, \\ and Beijing Normal University, Beijing 100101, China; \\ ${ }^{2}$ Ministry of Education Key Laboratory for Earth System Modeling, Center for Earth System Science, Tsinghua University, \\ Beijing 100084, China; \\ ${ }^{3}$ College of Global Change and Earth System, Beijing Normal University, Beijing 100875, China; \\ ${ }^{4}$ Division of Ecosystem Science, University of California, Berkeley, CA 94720-3114, USA
}

Received December 13, 2011; accepted March 30, 2012; published online June 8, 2012

\begin{abstract}
Based on the same data source of Landsat TM/ETM+ in 1990s, 2000s and 2010s, all urban built-up areas in China are mapped mainly by human interpretation. Mapping results were checked and refined by the same analyst with the same set of criteria. The results show during the last 20 years urban areas in China have increased exponentially more than 2 times. The greatest area of urbanization changed from Northeastern provinces in 1990s to the Southeast coast of China in Jiangsu, Guangdong, Shandong, and Zhejiang in 2010s. Urban areas are mostly converted from croplands in China. Approximately $17750 \mathrm{~km}^{2}$ croplands were converted into urban lands. Furthermore, the conversion from 2000 to 2010 doubled that from 1990 to 2000. During the 20 years, the most urbanized provinces are Jiangsu, Guangdong, Shandong and Zhejiang. We also analyzed built-up areas, gross domestic production (GDP) and population of 147 cities with a population of greater than 500000 in 2009 . The result shows coastal cities and resource-based cities are with high economic efficiency per unit of built-up areas, resource-based cities have the highest population density, and the economic efficiency of most coastal provinces are lower than central provinces and Guangdong. The newly created urban expansion dataset is useful in many fields including trend analysis of urbanization in China; simulation of urban development dynamics; analysis of the relationship among urbanization, population growth and migration; studies of carbon emissions and climate change; adaptation of climate change; as well as land use and urban planning and management.
\end{abstract}

urban expansion, land use, cropland conversion, built-up areas

Citation: Wang L, Li C C, Ying Q, et al. China's urban expansion from 1990 to 2010 determined with satellite remote sensing. Chin Sci Bull, 2012, 57: 2802-2812, doi: 10.1007/s11434-012-5235-7

Urban land is the land cover type where most human activities occur with the greatest intensity of land use. With the growth of population and increase of wealth in the world, large number of people moves from rural to urban areas at an accelerating rate [1]. As a result, urban areas expand significantly. Urban expansion is a double sided sword. On one hand, it brings more convenience to human production and living. On the other hand, it has a lot of companion problems such as environmental pollution [2], traffic jam and

*Corresponding author (email: penggong@tsinghua.edu.cn) climate change at the local scale [3], which in turn affects agriculture [4-7], water resource [8], and the natural environment $[9,10]$, accelerates the spread of diseases $[11,12]$, and creates challenges for urban planning and management $[13,14]$. To meet these challenges, it is important to have timely information about urban expansion according to the same definition on urban boundaries, the same criteria and data sources. However, there exist a lot of inconsistencies in definitions of urban boundaries [15,16], use of data sources [17], methods of urban area extraction [18-24] and areas of interest are limited to part or only a single city [15,25-34]. 
The problems of definition inconsistency, multiple mapping methods, data and mapping area differences in time and space, seriously impede the construction of a standard dataset on urban expansion that could be used in support of research activities on climate change modeling, regional and national land use planning, environmental protection and public health studies. Therefore, it is necessary to map urban expansions in large areas with data from the same source during short time duration for temporal consistency, and with methods that are accurate.

Since the reform and open-door policy in 1978, initial reforms in early 1980s happened primarily in rural areas followed by urbanization beginning in late 1980s. Urbanization in China gained acceleration in 1992 when DENG Xiaoping visited Southern China and promoted special economic zones in Shenzhen and Shanghai. Therefore, it is necessary to map urban expansions of all cities in China since the year 1990. In the beginning of the 21st century, urbanization in China gained unprecedented speed, the fastest in human history. Now more than half of the world's building materials are used in constructions in China, and this trend will continue until 2030 [35]. People lived in urban areas are grown from $19.7 \%$ in 1978 to $49.7 \%$ in 2010 $[36,37]$. As a result of the urbanization, croplands in China decreased dramatically and that placed a lot of threats to China's food security. However, how many acres of land are developed due to urban expansion? The answers to this question are quite different between the official statistics and those derived from remotely sensed data $[21,38]$.

Urban areas can be observed from remotely sensed data with a resolution better than $100 \mathrm{~m}$, and results obtained from remote sensing are more objective. Using such data properly, we can avoid the subjectivity in and manipulation by different levels of statistical bureaus. Here, we mainly use human interpretation method to map all 663 cities in China. Remotely sensed data are acquired by Landsat Thematic Mapper (TM) and enhanced TM plus (ETM+) that have similar spectral characteristics. Images acquired near 1990, 2000 and 2010, respectively have been collected. We also analyzed the magnitude and speed of urban expansion, estimated the amount of croplands occupied by urban development, and the economic efficiency of urban expansion.

\section{Mapping methods}

The scope of the mapping is the built-up areas where the city governments are located. For the urban-rural transitional areas, we consider built-up areas within 5 pixels as part of the urban areas, excluding those just connected by roads [39].

Urban areas have complex components, such as buildings, roads, green areas, water bodies and bare lands. Although automatic methods have been developed to map urban land use for individual cities for a long time [18,40], there are four difficulties in mapping urban expansions in large areas. First, the inconsistency of acquisition time in the remotely sensed data, which makes it difficult to apply a uniform automatic method to extract urban areas. Second, the uncertainty of spectral characteristics in urban areas due to the use of various kinds of building materials, which makes it hard to describe urban areas in a way that can be easily understood by image analysts. This always makes it difficult when mapping is done by multiple interpreters. Third, urban areas are confused with other land cover types. For example, high density buildings are confused with bare land sometimes, while low density building can be easily classified into other land types in rural areas. Last, in many large cities with intensive urbanization, it is hard to exclude croplands and other non-urban lands distributed at the city boundaries.

Although human interpretation is time-consuming, it is the most accurate method to overcome the above difficulties. In this study, a group of people delineated urban areas according to the same set of criteria and finally one analyst checked and refined the results with a consistent standard. After interpreting urban boundaries, we excluded croplands, rivers and mountain areas from the urban areas. Although some cities have counties, large towns or villages that are comparable in size, we did not take them into consideration.

China has 663 cities [41,42], including 654 cities in mainland China, 7 cities in Taiwan, plus Hong Kong and Macao. City names of this dataset are obtained from The Statistical Yearbook of Chinese Cities in 2009. We also considered data from Google Earth and the Provincial Atlas of China. All of the data and mapping results are in Albers-Krasovsky equal area projection.

The base years of urban area mapping are 1990, 2000 and 2010. We collected Landsat TM/ETM+ data during 1986-1994, 1999-2002 and 2008-2010 as the base data source. Satellite data are mostly downloaded free of charge from websites such as the http:/glcfapp.glcf.umd.edu:8080/ esdi/index.jsp, http://edcsns17.cr.usgs.gov/NewEarthExplorer/, and http://ids.ceode.ac.cn/query.html. Only 10 scenes were purchased from the Chinese Landsat Receiving Station to make up the gaps. Since the ETM+ images in 2000 period are ortho-rectified, and some of the data in 2010 were geocorrected to the 2000 data, we took the ETM+ data as the reference data. For data in circa 1990 and 2010 periods, we checked and did geo-rectification when necessary. Since our purpose was to map urban areas, control points were selected mainly near the city areas, to ensure that the registration errors to be within a pixel.

In the interpretation, we used ArcMap 9.3.1, the band composite for visualization are band 5, band 4 and band 3 in TM/ETM+ data shown in red, green and blue. The scale was under 1:50000. Initial results were done by three well-trained persons. The order of mapping was circa 2010, 2000 and 1990. Keeping comparison with the high resolution data (better than $2.5 \mathrm{~m}$ ) in Google Earth, we took the 
results of 2010 as a constraint for area when interpreting images in circa 2000 and 1990. In order to reduce uncertainties, one person did the final checking and refinement of every city initially interpreted.

In order to get accurate results of urban expansions at several sparsely distributed cities such as Shanghai, Beijing and Dongguan, which are expansively developed, we applied an automatic method to get the urban expansions [43-45]. Since the scope of the three urban expansion is no longer confined to the municipal districts, we make clear the scope of mapping as follows: mapping of Beijing covers the area of Beijing municipal district, Changping District, Shunyi District, Tongzhou District and Daxing District, with the scene ID being 123032 and 123033 for TM/ETM+ images; mapping of Shanghai include the area of Shanghai municipal district (excluding Chongming Island), Jiading District, Qingpu, Songjiang District, Minhang and Nanhui County which are located within scenes 118038 and 118039; mapping of Dongguan covers the whole territory of Dongguan, within scene 122044. Training sample selection in the classification process has four main categories, namely urban areas, bodies of water, bare soil and vegetation. On the basis of spectral reflectance, those four categories are divided into a number of subclass, 3-4 polygons are selected for training for each subclass. The maximum likelihood classifier is adopted for image classification. Slope information for each pixel is calculated based on $90 \mathrm{~m}$ Shuttle Radar Topographic Mission (SRTM) elevation data, and then resampled to $30 \mathrm{~m}$. Watershed segmentation algorithm is utilized to segment the images; those patches with less than 10 pixels are merged into its most similar neighboring patches. Those patches $50 \%$ of whose pixels are less than $5^{\circ}$, as well as $50 \%$ of whose pixels are classified as urban are considered to be urban areas. Ten urban and non-urban areas of each image are selected for validation. The overall accuracy of 15 images surpassed $90 \%$. With the fundamental assumption that cities are expanding during 1990 to 2010, the classification result of 2010 is used to restrict the results of 2000 and 1990, and meanwhile the result of 2000 is used to restrict the result of 1990 to mini- mize the uncertainty of automatic classification

Figure 1 shows the data distribution. The numbers above the bars are the number of cities interpreted in that year. The ideal case is all of the cities are in the same year. However, due to cloud and data acquisition limits, this is impossible. We have to choose data collected near the base year. For the 1990 period, 628 of 663 cities were mainly interpreted in 1987-1992. For the 2000 period, all cities were interpreted in 1999-2002. For the 2010 period, all cities were interpreted in 2008-2010. Specifically 488 cities were interpreted in 2009.

\section{Accuracy analysis}

The mapping products cover a long temporal period and large spatial scale. It is difficult to validate the results by field checking for each city. However, interpretation results from high resolution images available from Google Earth can be used instead of field works. When interpreting the urban areas, we used high resolution data (within $2.5 \mathrm{~m}$ ) for reference. In order to understand the quality of this work, we asked several other experienced interpreters to interpret $5 \%$ of the cities that were randomly selected based on the high resolution imagery in Google Earth. Comparing with the two independent sets of results, we found that the area differences were less than $10 \%$ with the same mapping standard. The resultant area from TM/ETM+ is bigger than that from Google Earth. There are four possible reasons. First, mixture effects cause some inaccuracies and make the boundaries a little bigger in the coarser resolution TM/ETM+ data. Second, bare land was confused with urban areas in TM/ETM+ data and was interpreted as urban areas. Third, in the rural-urban fringes, some rural areas were interpreted as urban areas due to low spatial resolution in the TM/ETM+ data. Fourth, in the Yangtze delta, it is difficult to determine the boundary of urban areas due to high river density and connected build-up areas along the water network (Figure 2(d)). Figure 2 shows results for Hohhot, Shaoxing, Shenzhen and Chengdu from TM/ETM+ data

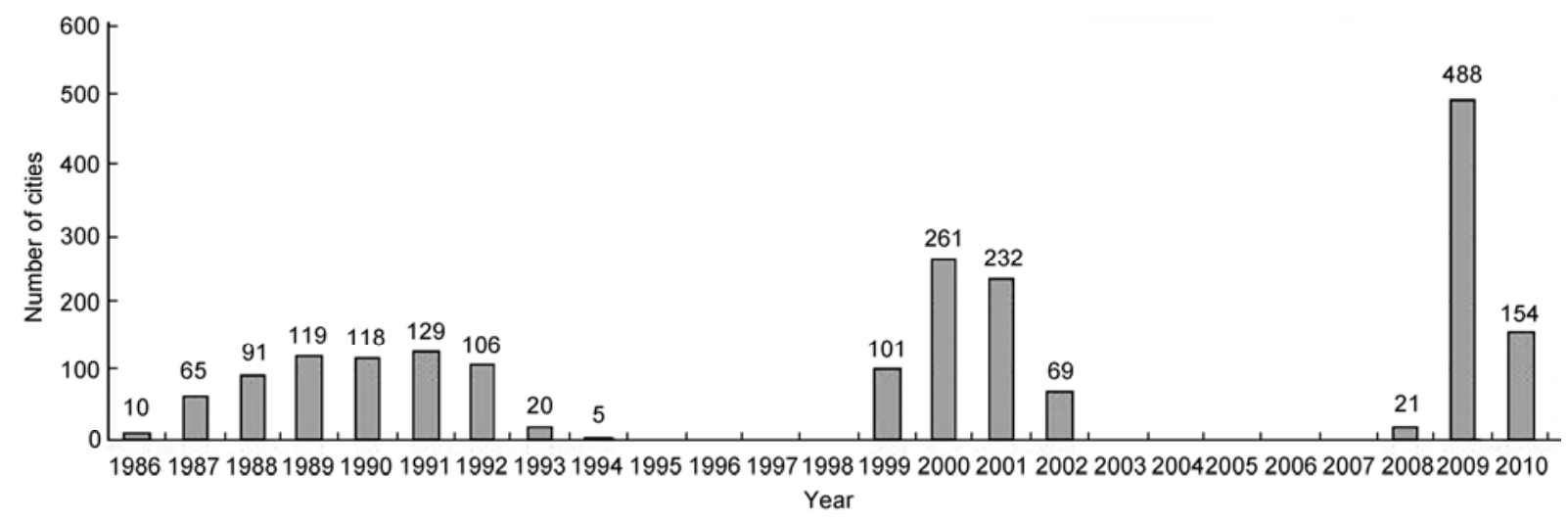

Figure 1 Temporal distribution of data used for urban area interpretation in circa 1990, 2000 and 2010. 

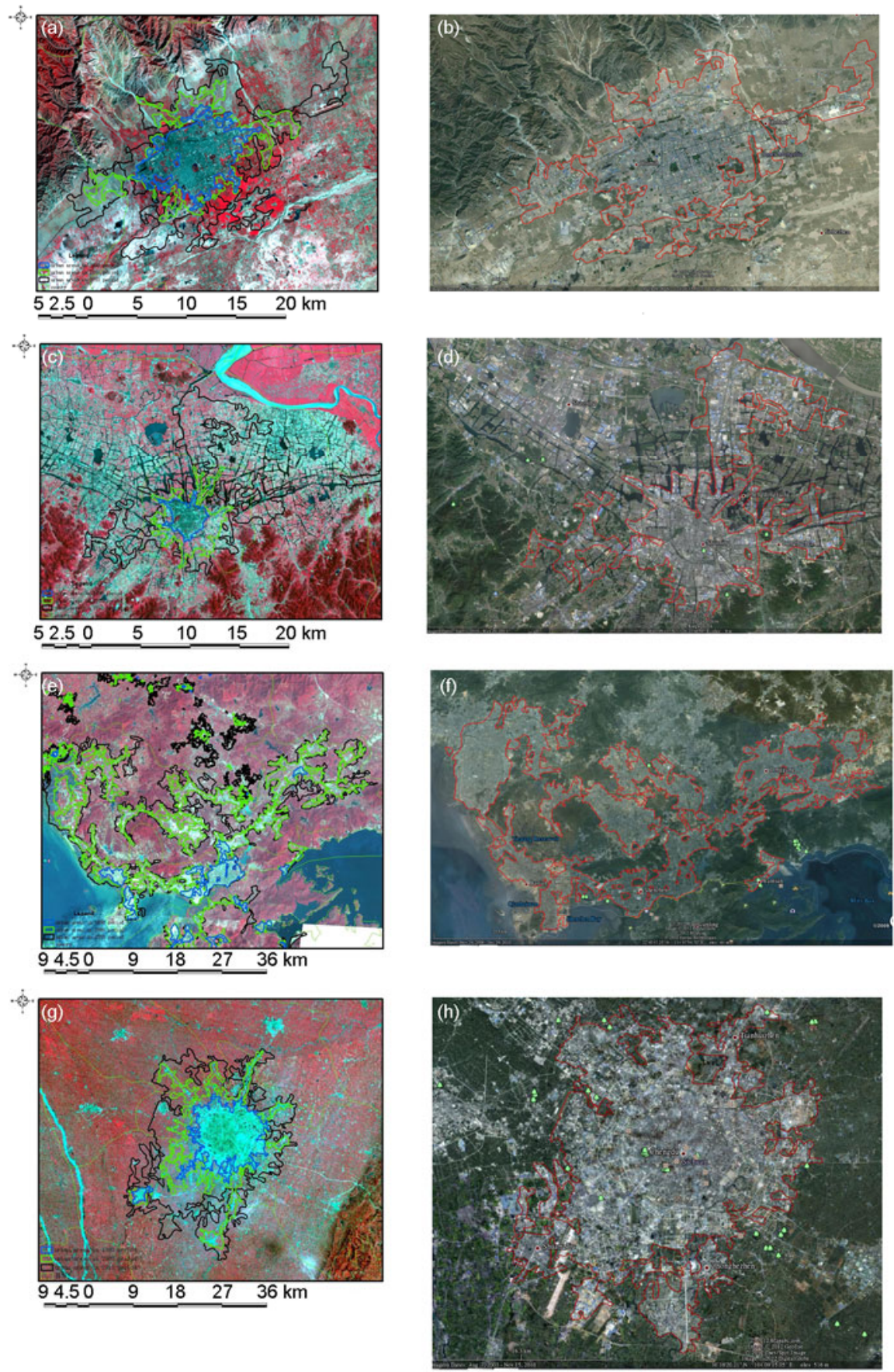

Figure 2 The agreement between the interpretation results from TM/ETM+ data with the corresponding high-resolution images in Google Earth as the background. (a) Hohhot, the TM data over Hohhot City acquired on September 15, 1987 were shown in the standard composites, with band 4, band 3, and band 2 respectively displayed with the red, green and blue color guns. The interpretation results of three periods were overlaid on this image; (b) interpretation result of 2010 period in (a) (July 25, 2009) overlaid on Google Earth high resolution image of Hohhot acquired on August 31, 2009; (c) Shaoxing, the TM data over Shaoxing City acquired on July 23, 1991, others are the same as in (a); (d) interpretation result of 2010 period in (c) (January 13, 2009) overlaid on Google Earth acquired on January 14, 2010; (e) Shenzhen, the TM data over Shenzhen City acquired on October 13, 1990, others are the same as in (a); (f) interpretation result of 2010 period in (e) (February 3, 2009) overlaid on Google Earth image acquired on April 30, 2010; (g) Chengdu, the TM data over Chengdu City acquired on September 15, 1987, others are the same as in (a); (h) interpretation result of 2010 period in (g) (March 24, 2009) overlaid on Google Earth of February 29, 2008. In (a), (c), (e) and (g), urban boundaries were presented for three periods with the 1990 period shown in blue, 2000 period shown in green, and 2010 period shown in dark. The boundary of counties is shown in green. The Hohhot City is the provincial capital of a low economic development province, and the urban area expanded by 2.58 times during the 20 years. The city of Shaoxing is located in southeast coastal area. The urban area expanded from $11 \mathrm{~km}^{2}$ in 1990 to more than $110 \mathrm{~km}^{2}$, expanding by 9.38 times. The city of Shenzhen is the most rapidly developing city. In 1990 it expanded from a fishing village to $62 \mathrm{~km}^{2}$, while in 2010 it expands to $692 \mathrm{~km}^{2}$, expanding by 10.25 times. The city of Chengdu is the biggest city in the Sichuan plain. In 1990 it was $113 \mathrm{~km}^{2}$, in 2000 it only added $115 \mathrm{~km}^{2}$, but in 2010, it expanded to $498 \mathrm{~km}^{2}$. 
overlaid on high resolution images in Google Earth. The dates between TM/ETM+ data and imagery from Google Earth were similar and it can be seen that the results agree well with the urban expansion observable from the Google Earth images.

\section{Analysis of the mapping results}

Figure 3 shows statistics at provincial level for urban built-up areas. In 1990, the 5 administrative regions with the greatest amount of urban areas were Beijing, Liaoning, Shandong, Jiangsu, and Guangdong. In 2000, the greatest 5 became Guangdong, Shandong, Jiangsu, Beijing and Liaoning. In 2010, the greatest 5 became Jiangsu, Guangdong, Shandong, Zhejiang and Beijing. The old industrial base constituting major urban areas in northeast provinces, has given way to more rapidly developed southeast costal provinces and Beijing during the 20 years. The build-up areas of cities in China expand from $12253 \mathrm{~km}^{2}$ in circa 1990, to $21848 \mathrm{~km}^{2}$ in circa 2000 and finally to $40534 \mathrm{~km}^{2}$ in 2010 . The areas in circa 2000 expanded $78.3 \%$ compared with the areas in 1990, while the areas in 2010 expand $85.5 \%$ from 2000. During the 20 years, the urban areas expanded 2.31 times than that in 1990.

Figures 4-6 show the built-up areas of each city in different size classes with provincial statistics of different levels in the background for circa1990, 2000 and 2010, respectively. In Figure 4 (circa 1990), there are only 4 cities whose built-up areas were greater than $200 \mathrm{~km}^{2}$, while 44 cities between $50-200 \mathrm{~km}^{2}$. That accounts for $7.2 \%$ of the total number of cities. Only Beijing had more than 1000 $\mathrm{km}^{2}$ of total urban areas. In Figure 5 (circa 2000), there are 14 cities greater than $200 \mathrm{~km}^{2}, 71$ cities between $50-200$ $\mathrm{km}^{2}$. That is $12.8 \%$ of the total number. Seven provinces have greater than $1000 \mathrm{~km}^{2}$ total urban areas. In Figure 6 (circa 2010), there are 43 cities greater than $200 \mathrm{~km}^{2}, 129$ cities between $50-200 \mathrm{~km}^{2}$. That is $25.9 \%$ of the total number. Thirteen provinces have greater than $1000 \mathrm{~km}^{2}$ of total urban areas.

Figure 7 shows urban expansions at the provincial level and area of croplands converted into urban from 1990 to 2000 and from 2000 to 2010. The cropland data were from the land cover/land use map produced from image interpretation of similar Landsat data in the 1980s (1:100000) [38]. From 1990 to 2000, urban areas expanded by $9602 \mathrm{~km}^{2}$, occupying about $5130 \mathrm{~km}^{2}$ croplands, which is $53.4 \%$. From 2000 to 2010, urban areas expanded by $18377 \mathrm{~km}^{2}$, occupying $12620 \mathrm{~km}^{2}$ croplands, which is $68.7 \%$. The last ten years saw a 1.46 times of cropland occupancy than the former ten years. From 1990 to 2000, the 5 most urbanized provinces are Guangdong, Shandong, Jiangsu, Zhejiang and Liaoning, while the 5 administrative regions consuming the greatest acreage of croplands are Guangdong, Shandong, Jiangsu, Zhejiang and Shanghai. From 2000 to 2010, the 5 most urbanized administrative regions are Jiangsu, Shandong, Zhejiang, Guangdong and Beijing, while the 5 administrative regions consuming the greatest acreage of croplands

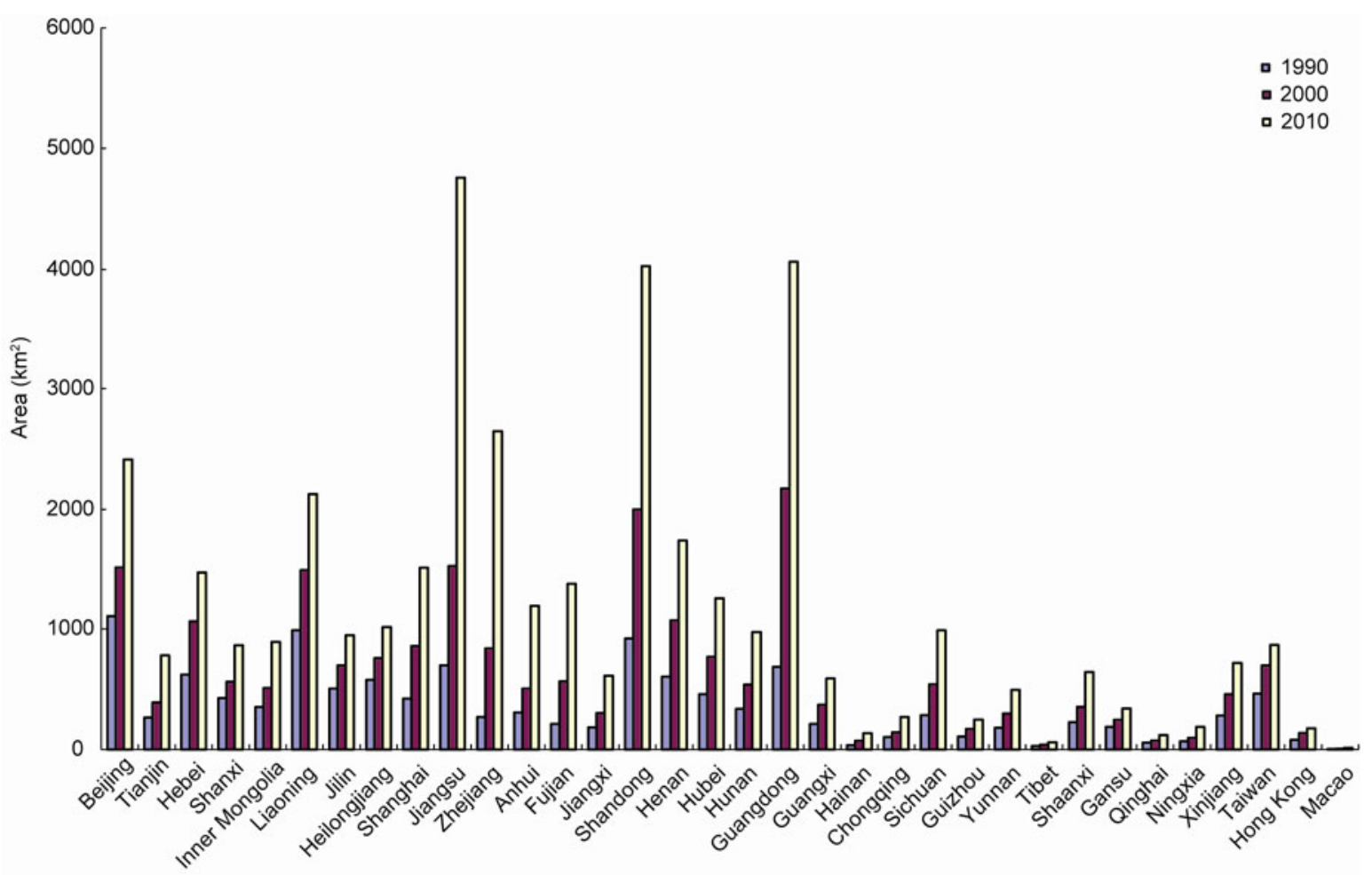

Figure 3 Administrative region statistics of built-up areas in China in 1990, 2000 and 2010 periods. 


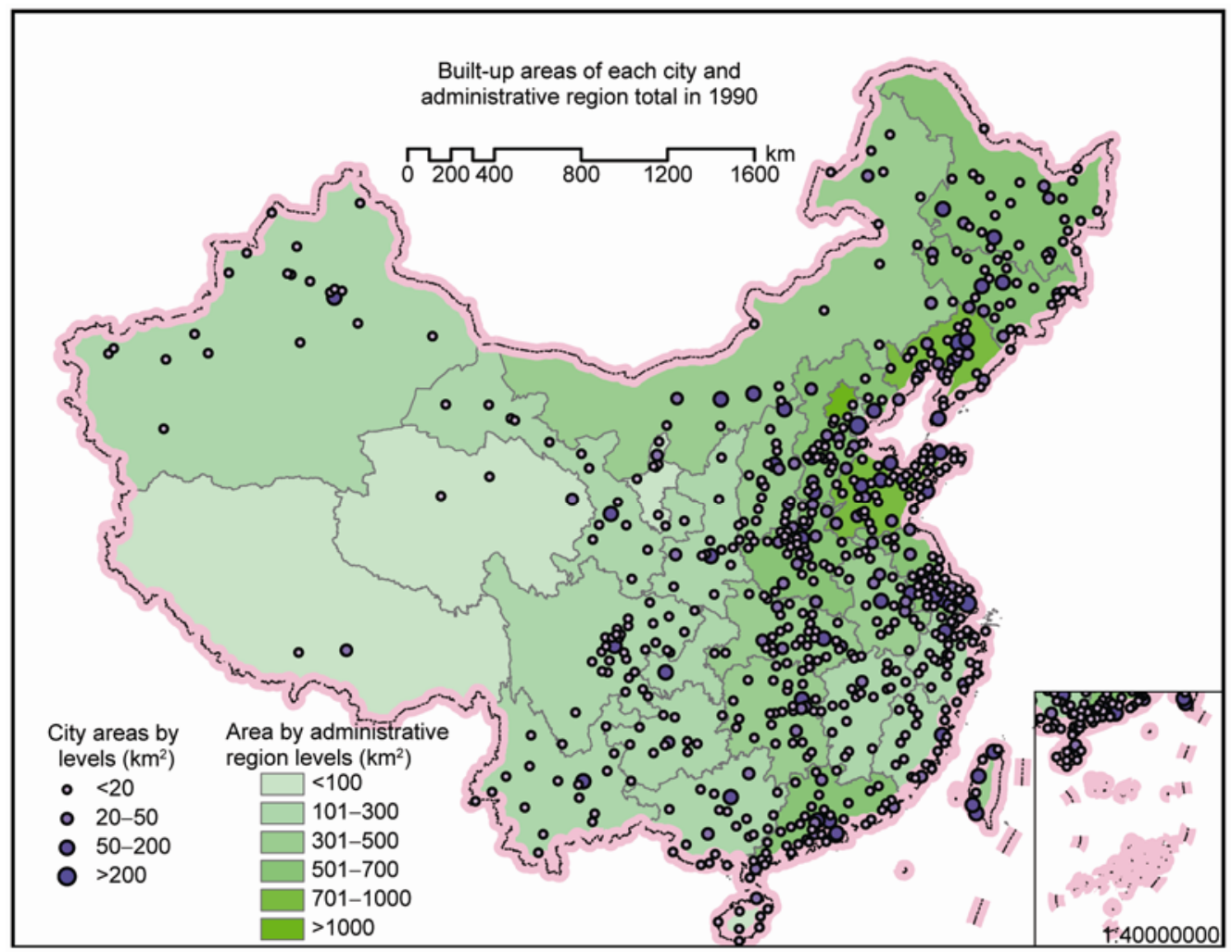

Figure 4 Built-up areas of each city in different size classes and administrative region total of different classes in the background for 1990 period.

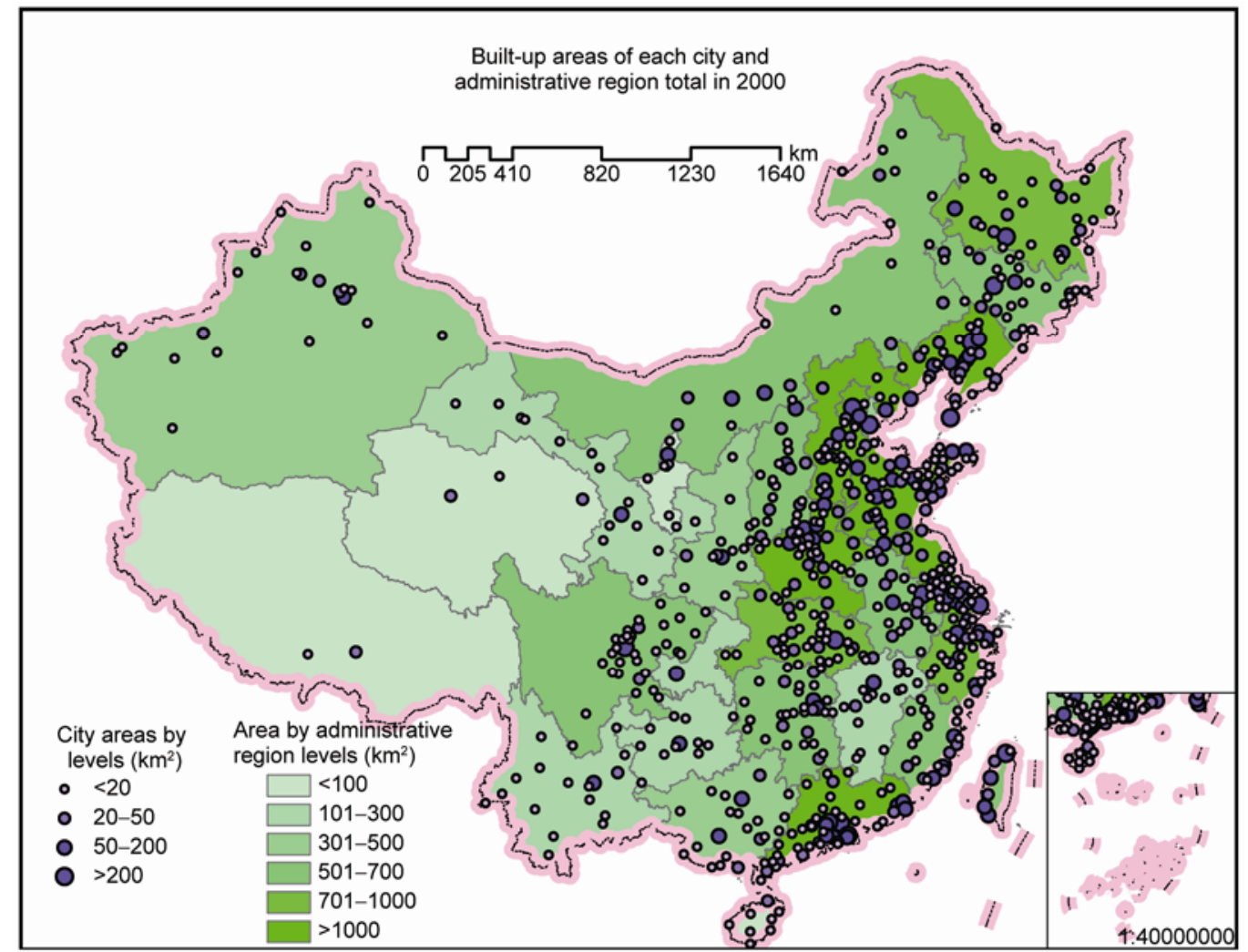

Figure 5 Built-up areas of each city in different size classes and administrative region total of different classes in the background for 2000 period. 


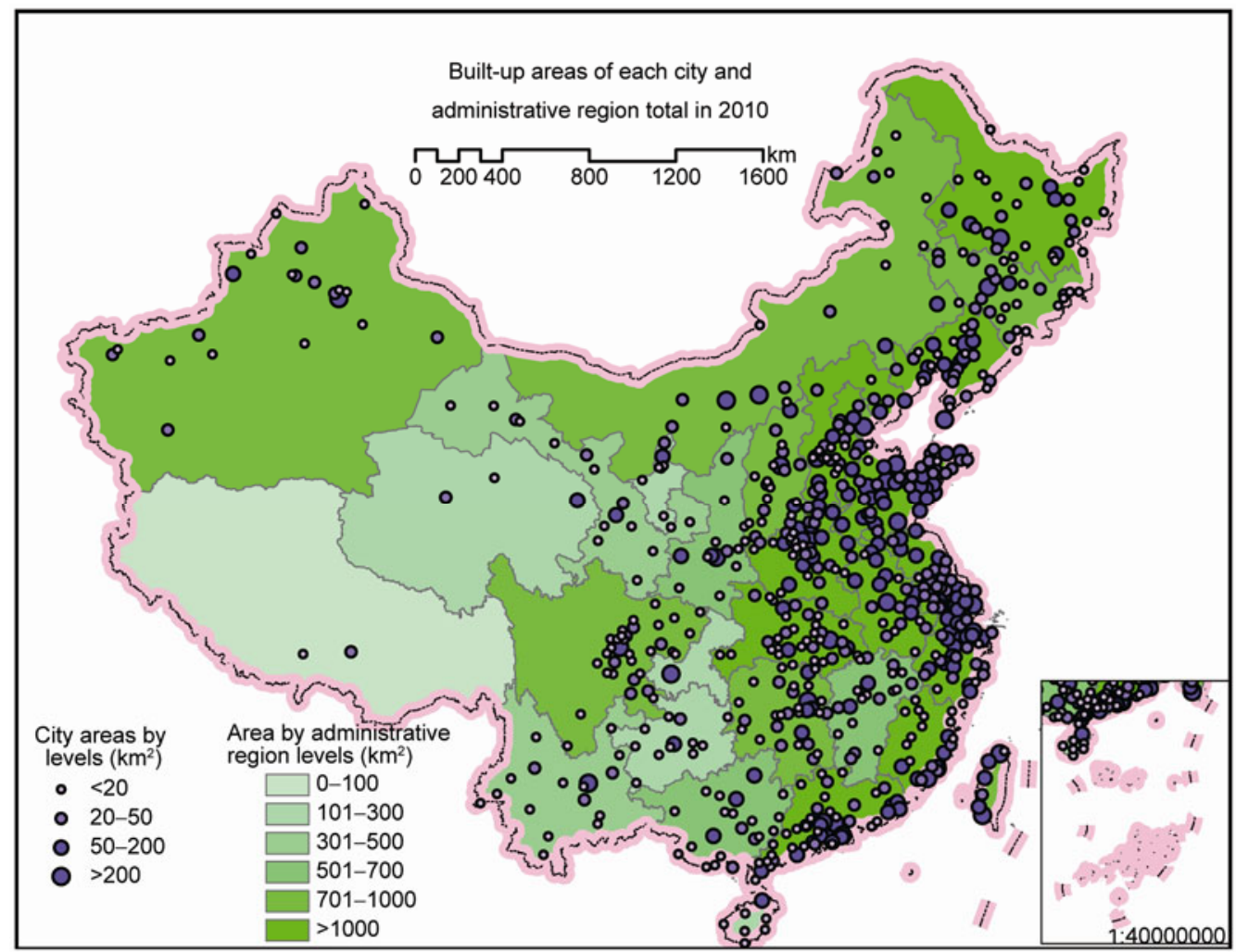

Figure 6 Built-up areas of each city in different size classes and administrative region total of different classes in the background for the 2010 period.

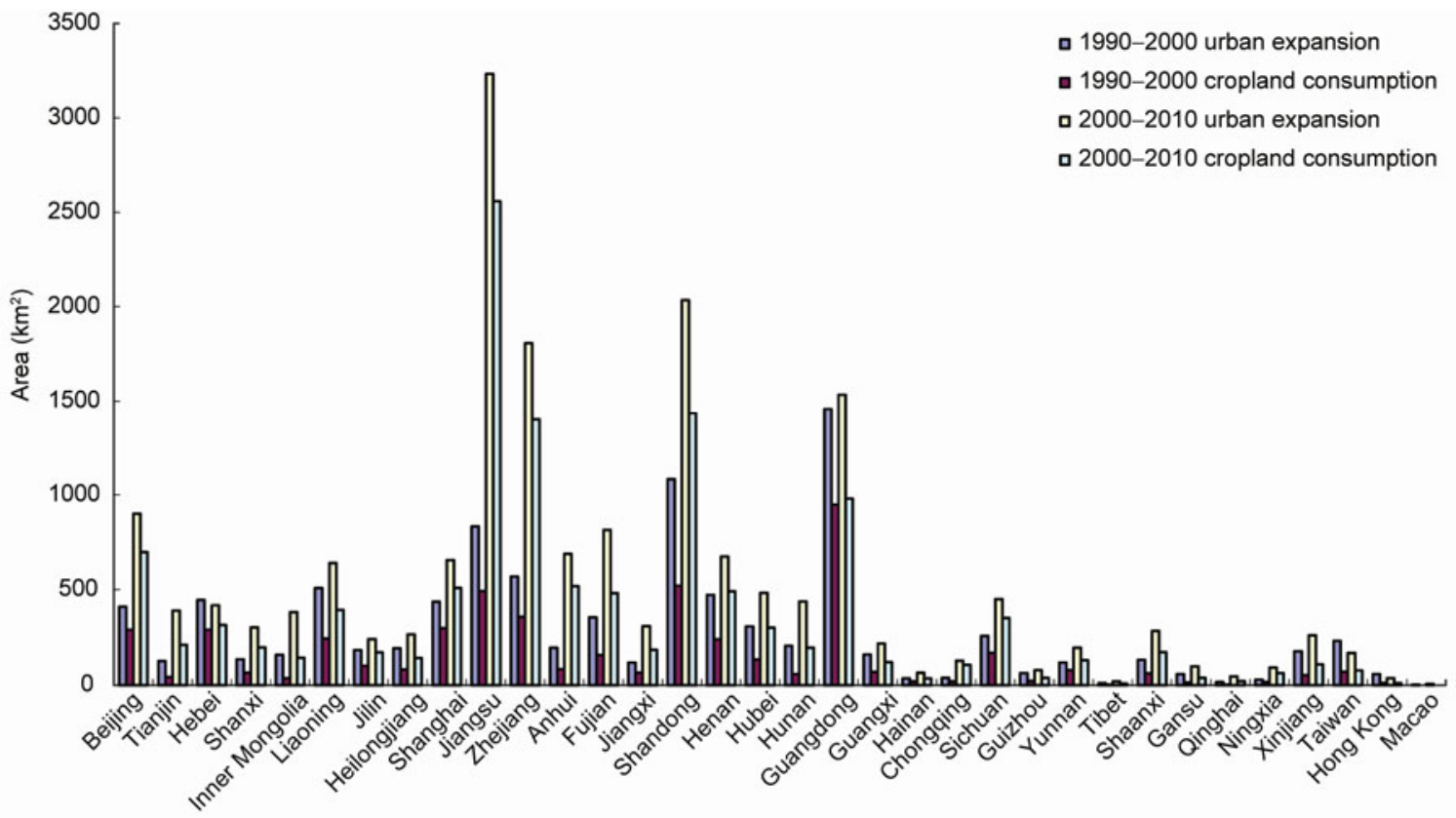

Figure 7 Magnitudes of urban expansion and cropland consumption at administrative regions during 1990-2010.

are also these 5 administrative regions. It can be seen that Jiangsu, Shandong, Guangdong and Zhejiang are the most urbanized provinces, which also consumed most croplands during the urbanization process of the 20 years.

From 1990 to 2010, the speed of urbanization in different cities is largely different. The 9 cities including Yongcheng, Cixi, Shangyu, Jinjiang, Kunshan, Fuyang, Zhangjiagang, Zhuji, Jimo have expanded more then 20 times, mainly distributed in Jiangsu, Zhejiang and Shandong provinces. The 19 cities such as Dongxing, Yiwu, Jiangyin, Fuqing, Ningbo, 
Yuyao have expanded 10 to 20 times, while 66 cities including Quzhou, Shaoxing, Suqian, Changshu, Suzhou, Xiamen, Shanghai, Nanjing, have expanded 5 to 10 times. Figure 8 shows the speed of the city expansions during the 20 years. Cities with high urbanization rates are in Jiangsu, Zhejiang, Shandong, Guangdong, Fujian and Sichuan. Cities in northeast China had high urbanization level in 1990, but they did not expand much. Except Sichuan Province, cities in central and northwest provinces have not expanded much, nor cities in Taiwan and Hong Kong.

\section{Land use efficiency of urban expansion}

GDP data were collected in the same year as the mapping time of urban areas. We analyzed relationships among urban areas, populations and GDP of the 147 large cities in China whose populations were greater than 500000. All data are shown in the appended table. These data are from "China City Statistical Yearbook" and "China City Construction Statistical Yearbook". Overall, the urban population density in China decreased from 17100 persons $/ \mathrm{km}^{2}$ in 1990 , to 13000 persons $/ \mathrm{km}^{2}$ in 2000, and to 12200 persons $/ \mathrm{km}^{2}$ in 2010 . The lowered population density means improvement in people's living condition. Meanwhile, the GDP/ $/ \mathrm{km}^{2}$ increased from 79 million Yuan in 1990, to 297 million Yuan in 2000, and to 705 million Yuan in 2010. However, the urban areas have expanded faster in 2000-
2010 than 1990-2000 and yet the per square kilomenter GDP increase did not catch up with this acceleration in urban expansion. Thus, there is a drop in economic efficiency of built-up area per unit area for the last 10 years as compared to the first ten year.

Figure 9 shows the state of each city and the provincial average GDP per unit of urbanized area in 2009, while Figure 10 shows the state of each city and provincial average population per unit of urbanized area in 2009. A high value in GDP per unit of built-up area means a high efficiency of a particular city or province, while the high value of population per unit of built-up area means the situation of land saving by a city or province. Since the population density and GDP have complex relationship with the living quality of the city, we did not intend to make much analysis in this research. In 2009, the GDP/ $\mathrm{km}^{2}$ exceeded 2 billion Yuan in Panzhihua, Erdos, Foshan, Daqing and Taizhou, while Hui zhou, Chongqing, Zhuhai, Zaozhuang, Tangshan, Changde, Luzhou, Shantou, Guangzhou, Yichang, Zhongshan, Benxi, Shenzhen, Hangzhou, Qingdao, Zhenjiang, Yueyang, Wenzhou, Zigong and Nanchang exceeded 1 billion Yuan. All of these cities are resource-based cities or developed cities in the coastal areas.

In 2009, Panzhihua, Yichun, Tianshui, Shantou, Erdos and Jixi had more than 30000 persons $/ \mathrm{km}^{2}$, while Luzhou, Chongqing, Taizhou, Nanchong, Zigong, Zunyi, Huizhou, Benxi, Zaozhuang, Yiyang, Huainan, Zhangjiakou, Hengyang and Nanchang had more than 16500 persons $/ \mathrm{km}^{2}$. All

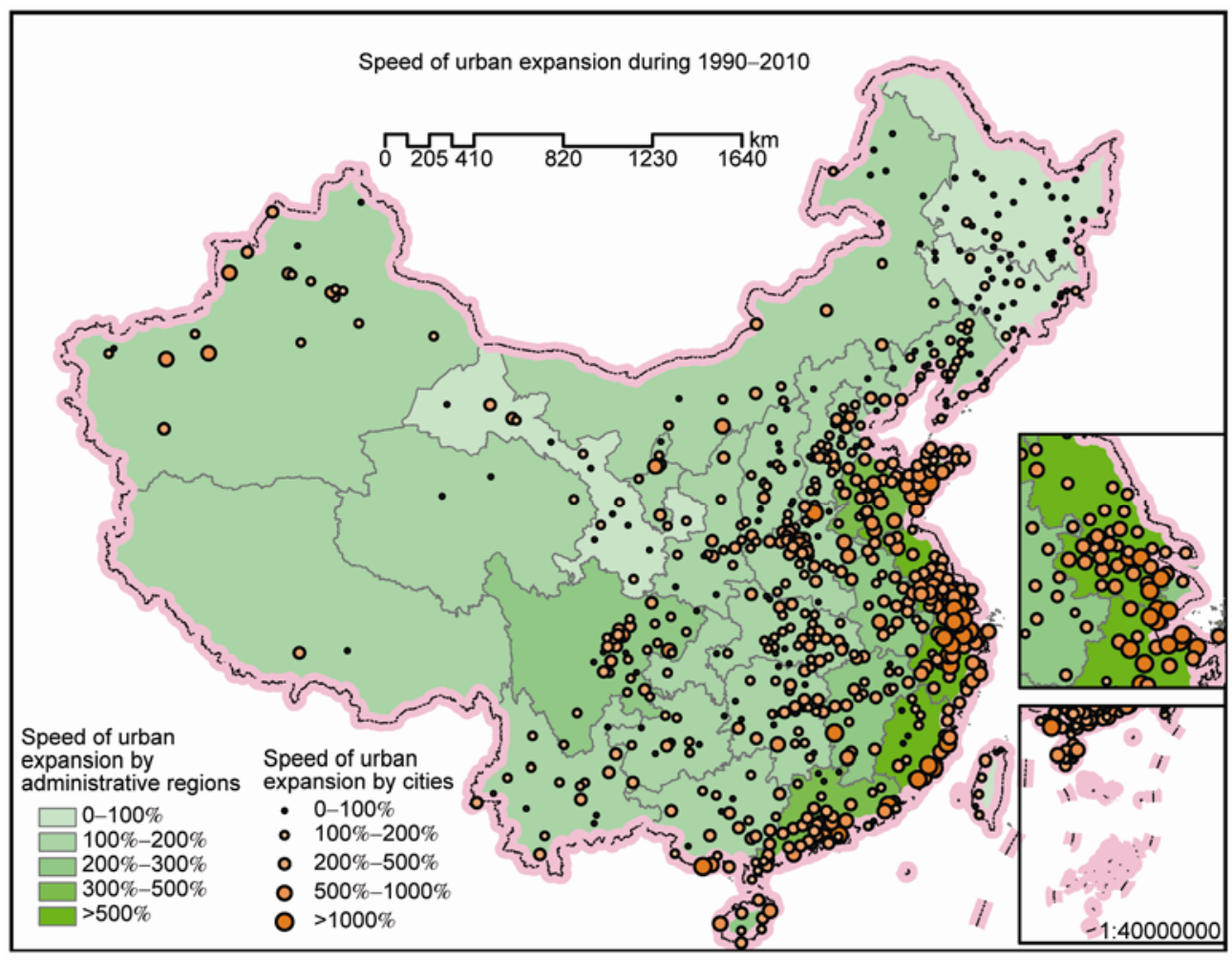

Figure 8 Speed of urban expansion during the 20 years. 


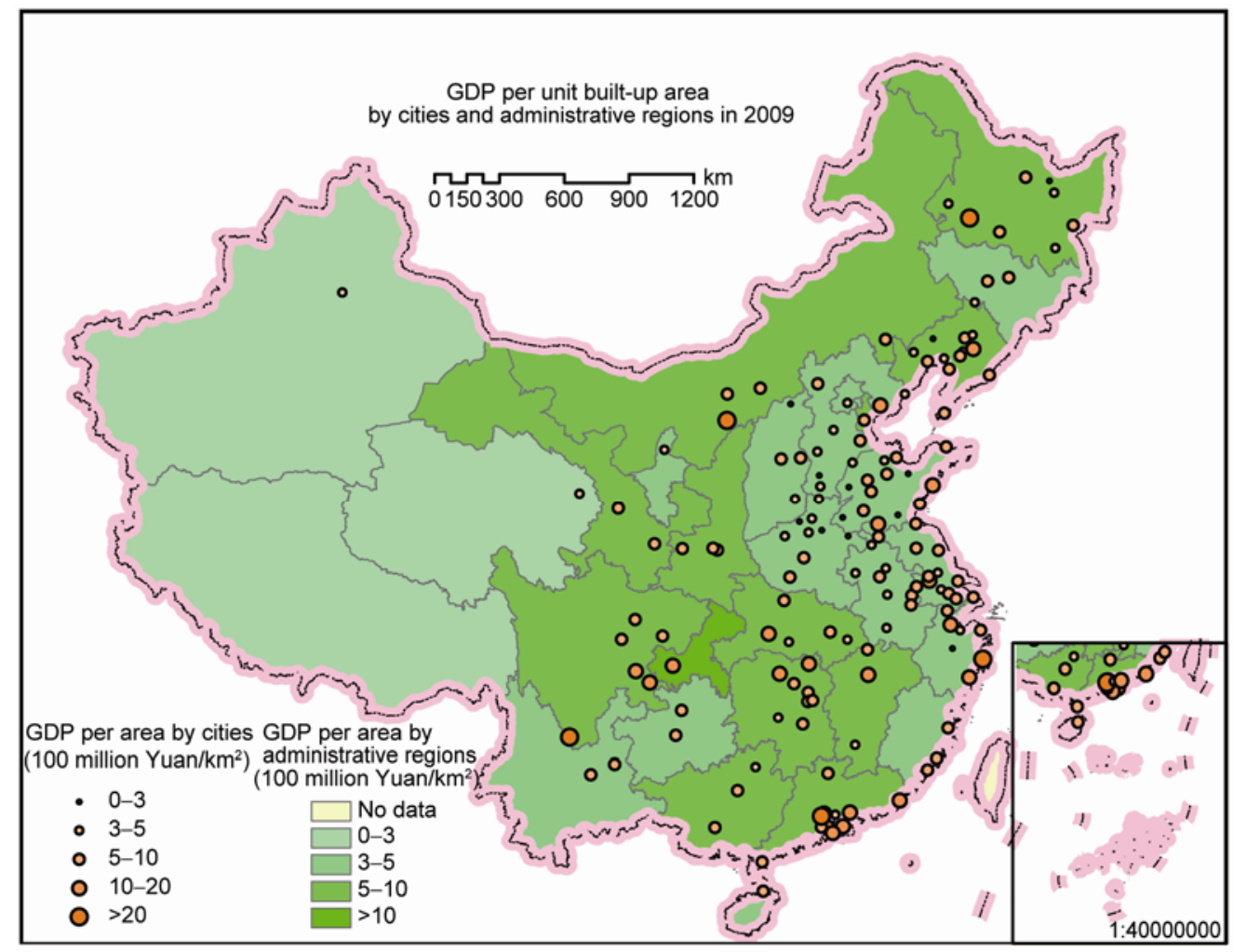

Figure 9 GDP per unit built-up area of cities and administrative regions in 2009.

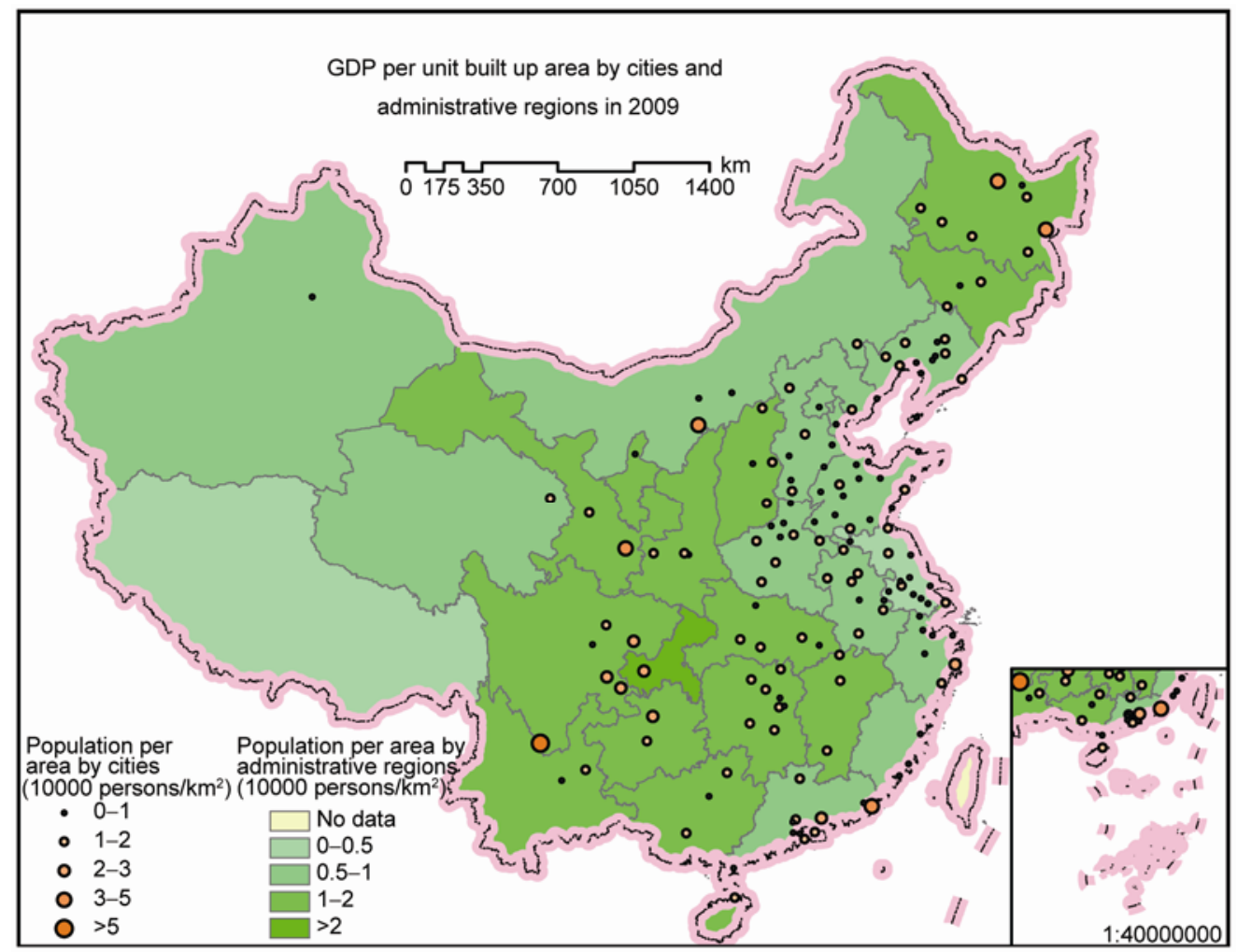

Figure 10 Population per unit built-up area of cities and administrative regions in 2009. 
of these cities are old resource-based industrial cities or under developed cities.

From Figures 9 and 10, by provincial statistics, the most economically built-up areas and high urban population density provinces is Chongqing. The coastal southeast provinces had lower GDPs $/ \mathrm{km}^{2}$ compared with central provinces and Guangdong.

\section{Discussion and conclusions}

Based on the same data type of Landsat TM/ETM+ in the 1990s, 2000s and 2010s, we mapped the built-up areas of all the cities in China mainly by human interpretation. The results show during the last twenty years urbanization in China has increased exponentially by more than 2 times. The most built-up areas changed from the northeastern Provinces in 1990 to the southeast coast of Jiangsu, Guangdong, Shandong and Zhejiang in 2010. Urbanization lands are mostly converted from croplands in China. About 17750 $\mathrm{km}^{2}$ of croplands were converted into urban land. Furthermore, the conversion from 2000 to 2010 is 1.46 times that from 1990 to 2000. During the 20 years, the most urbanized provinces are Jiangsu, Guangdong, Shandong and Zhejiang.

We analyzed built-up areas, GDP and population of 147 cities with a population of greater than half a million. The result shows that coastal cities and resource-based cities have high economic efficiency of built-up areas, while resource-based inland cities have high population per square kilometer. Costal developed cities, whose economies are diversified, can support high population and high GDP/ $/ \mathrm{km}^{2}$ with large built-up areas. However, resource-based (such as oil, coal, steel) cities, whose population structure in occupation is uniform with high densities, tend to have small sizes of built-up areas. Therefore, they have high population densities with high GDP/ $\mathrm{km}^{2}$. Those cities with high GDP/ $\mathrm{km}^{2}$ and medium population densities have the high qualities of living. Seven out of the twenty cities with the highest GDP $/ \mathrm{km}^{2}$ are located in Guangdong and none of them are located in the Yangtze River Delta. Although Shanghai and Jiangsu have added more urban areas than those in Guangdong, the GDP $/ \mathrm{km}^{2}$ in Shanghai and Jiangsu are much lower than that in Guangdong. The GDP/ $\mathrm{km}^{2}$ in Shanghai, Nanjing, Suzhou, Wuxi, and Changzhou are ranked the 27th, 72nd, 81st, 90th and the 112th, respectively. Beijing ranked the 101st. This trend should be noted and must change. Shanghai, Suzhou and Kunshan, as well as Guangzhou, Dongguan and Shenzhen, have grown together. These megacities should make full use of resources, improve the efficiency of land use and reduce the traffic time of their citizens. However, most cities want large and all-rounded development, and cities administrated by different provinces are more likely to waste land. Take Qingdao as an example, the main part of Qingdao, Jiaozhou, Jimo belonging to the same prefecture have already connected with each other by urban expansion. We can predict examples like that will increase in China. Planning between cities, increasing the use efficiency of built-up areas, will be an important issue of future urban planning and perhaps inter-urban planning.

During 1990 and 2010, the trend of urban built-up areas in China has expanded exponentially, and has occupied more croplands. Together with the expansion of rural built-up areas, urban expansions would have an increasing impact on China's food security. This has attracted attention by people from many sectors of the society [46]. However, how much exactly is the impact of urbanization on agriculture, climate and the environment? It has not been well answered in the past. The mapping product on built-up areas of cities provides a base for answering that question. The dataset has been done by the same group, with the same method, using the same type of data, and checked and refined each city by the same person. The precise delineation of built-up areas cannot be found in published yearbooks. This dataset is helpful to many fields, such as the study on the trend of urbanization in China and the trend of land conversion from croplands and other lands into urban areas, the simulation of the dynamic development of cities, the study on the relationship of urbanization, population growth and migration, the analysis of carbon emissions and climate change, and policy making regarding potential climate change, land use planning and urban planning and administration. In mapping urban areas, we shall improve the accuracy, avoid or reduce errors from spectral uncertainties between bare land or croplands and high density settlement areas. We also need to further classify land use types within urban areas. These will be done in the future.

This work was supported by the National Natural Science Foundation of China (41001275), the Special Foundation for Young Scientists of State Laboratory of Remote Sensing Science (10QN-04) and National HighTech $R$ \& D Program of China (2008AA121702 and 2009AA12200101).

1 United Nations. World Urbanization Prospects: The 2007 Revision. New York: United Nations, 2008. 3-4

2 Zhang J F, Mauzerall D L, Zhu T, et al. Environmental health in China: Progress towards clean air and safe water. Lancet, 2010, 375: 11101119

3 Jin M, Dickinson R E, Zhang D L. The footprint of urban areas on global climate as characterized by MODIS. J Clim, 2005, 18: 1551-1565

4 Seto K C, Kaufmann R K, Woodcock C E. Landsat reveals China's farmland reserves, but they are vanishing fast. Nature, 2000, 406:121

5 Doygun H. Effects of urban sprawl on agricultural land: A case study of Kahramanmaras, Turkey. Environ Monit Assess, 2009, 158: 471-478

6 Su S L, Jiang Z L, Zhang Q, et al. Transformation of agricultural landscapes under rapid urbanization: A threat to sustainability in Hang-JiaHu region, China. Appl Geogr, 2011, 31: 439-449

7 Liu J Y, Zhan J Y, Deng X Z. Spatiotemporal patterns and driving factors of urban land expansion in China during the economic reform era. Ambio, 2005, 34: 450-455

8 Hosseini S A, Shahraki S Z, Farhudi R, et al. Effect of urban sprawl on a traditional water system in the city of Mashhad, NE Iran. Urban Water J, 2010, 7: 309-320

9 Lu D S, Xu X F, Tian H Q, et al. The effects of urbanization on net primary productivity in southeastern China. Environ Manage, 2010, 46: 
404-410

10 Guneralp B, Seto K C. Environmental impacts of urban growth from an integrated dynamic perspective: A case study of Shenzhen, South China. Global Environ Chang, 2008, 18: 720-735

11 Liang L, Xu B, Chen Y L, et al. Combining spatial-temporal and phylogenetic analysis approaches for improved understanding on global H5N1 transmission. PLoS One, 2010, 5: e13575

12 Gong P, Liang S, Carlton E, et al. Urbanization and health in China. Lancet, 2012, 379: 843-852

13 Chen J, Gong P, He C, et al. Assessment of urban development plan of Beijing by using CA-based urban growth model. Photogramm Eng Remote Sens, 2002, 68: 1063-1071

14 Batty M. The size, scale, and shape of cities. Science, 2008, 319: 769-771

15 Pham H M, Yamaguchi Y. Urban growth and change analysis using remote sensing and spatial metrics from 1975 to 2003 for Hanoi, Vietnam. Int J Remote Sens, 2011, 32: 1901-1915

16 Ferreira J A, Condessa B, e Almeida J C, et al. Urban settlement delimitation in low-density areas - An application to the municipality of Tomar (Portugal). Landscape Urban Plan, 2010, 97: 156-167

17 Griffiths $\mathrm{P}$, Hostert $\mathrm{P}$, Gruebner $\mathrm{O}$, et al. Mapping megacity growth with multi-sensor data. Remote Sens Environ, 2010, 114: 426-439

18 Gong P, Howarth P J. Land-use classification of SPOT HRV data using a cover-frequency method. Int J Remote Sens, 1992, 13: 1459-1471

19 Gong P, Marceau D, Howarth P J. A comparison of spatial feature extraction algorithms for land-use mapping with SPOT HRV data. Remote Sens Environ, 1992, 40: 137-151

20 Gong P, Howarth P J. The use of structural information for improving land-cover classification accuracies at the rural-urban fringe. Photogramm Eng Remote Sens, 1990, 56: 67-73

21 Wang L, Gong P, Ying Q, et al. Settlement extraction over North China Plain with Landsat and Beijing-1 data using an improved watershed segmentation algorithm. Int J Remote Sens, 2010, 31: 1411-1426

$22 \mathrm{Xu} \mathrm{B}$, Gong P. Land use/cover classification with multispectral and hyperspectral EO-1 data. Photogramm Eng Remote Sens, 2007, 73: 955-965

23 Yin J, Yin Z, Zhong H D, et al. Monitoring urban expansion and land use/land cover changes of Shanghai metropolitan area during the transitional economy (1979-2009) in China. Environ Monit Assess, 2011, 177: 609-621

24 Dai X Y, Guo Z Y, Zhang L Q, et al. Spatiotemporal pattern of urban land cover evolvement with urban renewal and expansion in Shanghai based on mixed pixel classification for remote sensing imagery. Int $\mathbf{J}$ Remote Sens, 2010, 31: 6095-6114

25 Catalan B, Sauri D, Serra P. Urban sprawl in the Mediterranean? Patterns of growth and change in the Barcelona metropolitan region 1993-2000. Landscape Urban Plan, 2008, 85: 174-184

26 Guo L Y, Wang D L, Qiu J J, et al. Spatiotemporal patterns of land use change along the Bohai Rim in China during 1985-2005. J Geogr Sci, 2009, 19: 568-576

27 Lü Z Q, Wu Z F, Wei J B, et al. Monitoring of the urban sprawl using geoprocessing tools in the Shenzhen municipality, China. Environ Earth
Sci, 2011, 62: 1131-1141

28 Seto K C, Kaufmann R C. Modeling the drivers of urban land use change in the Pearl River Delta, China: Integrating remote sensing with socio-economic data. Land Econom, 2003, 79: 106-121

29 Tian G J, Jiang J, Yang Z F, et al. The urban growth, size distribution and spatio-temporal dynamic pattern of the Yangtze River Delta megalopolitan region, China. Ecol Model, 2011, 222: 865-878

30 Wei Y P, Zhao M. Urban spill over vs local urban sprawl: Entangling land-use regulations in the urban growth of China's megacities. Land Use Policy, 2009, 26: 1031-1045

31 Xu C, Liu M S, Yang X J, et al. Detecting the spatial differentiation in settlement change rates during rapid urbanization in the Nanjing Metropolitan region, China. Environ Monit Assess, 2010, 158: 471- 478

32 Yang J, Zhao L S, McBride J, et al. Can you see green? Assessing the visibility of urban forests. Landscape Urban Plan, 2009, 91: 97-104

$33 \mathrm{Yu} \mathrm{W} \mathrm{H,} \mathrm{Zang} \mathrm{S} \mathrm{Y,} \mathrm{Wu} \mathrm{C} \mathrm{S,} \mathrm{et} \mathrm{al.} \mathrm{Analyzing} \mathrm{and} \mathrm{modeling} \mathrm{land} \mathrm{use}$ land cover change in the Daqing City, China. Appl Geogr, 2011, 31: 600-608

34 Fan F L, Wang Y P, Qiu M H, et al. Evaluating the temporal and spatial expansion of Guangzhou from 1979 to 2003 by remote sensing and GIS methods, Int J Geogr Inf Sci, 2009, 23: 1371-1388

35 Fernandez J E. Resource consumption of new urban construction in China. J Ind Ecol, 2007, 11: 99-115

36 Nation Bureau of Statistics, PRC. China's main demographic indicators from the 3rd national population census, 1982

37 Nation Bureau of Statistics, PRC. China's main demographic indicators from the 6th national population census, 2011

38 Liu J Y, Liu M L, Tian H Q, et al. Spatial and temporal patterns of China's cropland during 1990-2000: An analysis based on Landsat TM data. Remote Sens Environ, 2005, 98: 442-456

39 Zhou S Y, Zhu A X, Qiu W L, et al. GIS based connectivity analysis and its application in prime farmland protection planning (in Chinese). Trans Chin Soc Agr Engi, 2008, 24: 72-77

40 Gong P, Howarth P J. Frequency-based contextual classification and grey-level vector reduction for land-use identification. Photogramm Eng Remote Sens, 1992, 58: 423-437

41 Urban Social and Economic Investigation Division, National Bureau of Statistics of China. China City Statistical Yearbook (in Chinese). Beijing: China Statistics Press, 2010

42 Global Map Press. Provincial Atlas of China — Taiwan Province (in Chinese). Beijing: Global Map Press, 2008

43 Schneider A, Friedl M A, Potore D. Mapping global urban areas using MODIS 500-m data: New methods and datasets based on 'urban ecoregions'. Remote Sens Environ, 2010, 114: 1733-1746

44 Yang, L, Huang C, Homer B K, et al. An approach for mapping large-area impervious surfaces: Synergistic use of Landsat-7 ETM+ and high spatial resolution imagery. Can J Remote Sens, 2003, 29: 230-240

45 Li C, Wang L, Gong P, et al. Residential areas extraction method over large areas integrating supervised/unsupervised/contextual/object-based methods and auxiliary data with medium resolution remotely sensed data, Joint Urban Remote Sensing Event-Munich. 2011. 173-176

46 Gong P. China needs no foreign help to feed itself. Nature, 2011, 474: 7

Open Access This article is distributed under the terms of the Creative Commons Attribution License which permits any use, distribution, and reproduction in any medium, provided the original author(s) and source are credited.

\section{Supporting Information}

Table S1 Urban areas, populations and GDP of the 147 large cities in China whose populations are greater than 500000

The supporting information is available online at csb.scichina.com and www.springerlink.com. The supporting materials are published as submitted, without typesetting or editing. The responsibility for scientific accuracy and content remains entirely with the authors. 